\title{
The concept of estimation of elevator shaft control measurement results in the local 3D coordinate system
}

\author{
Daria Filipiak-Kowszyk ${ }^{1}$, Waldemar Gierski ${ }^{1}$, Waldemar Kaminski ${ }^{1}$, and Karolina Makowska ${ }^{1, *}$ \\ ${ }^{1}$ Gdansk University of Technology, Faculty of Civil and Environmental Engineering, Narutowicza St. 11/12, Gdansk, Poland
}

\begin{abstract}
Geodetic control measurements play an important part because they provide information about the current state of repair of the construction, which has a direct impact on the safety assessment of its exploitation. Authors in this paper have focused on control measurements of the elevator shaft. The article discusses the problem of determining the deviation of elevator shaft walls from the vertical plane in the local 3D coordinate system. It presents a concept of estimation of measurements results base on the parametric method with conditions on parameters. The simulated measurement results were used to verify the concept presented in the paper.
\end{abstract}

\section{Introduction}

An important aspect in the context of using the structure is to ensure its safety. For this reason, geodetic control measurements are made in order to obtain information about the structure behaviour $[1,2]$.

The process of building an elevator shaft is a very demanding venture. The construction has to comply with a number of conditions to ensure its proper operation and safety in the future. The whole system of an elevator consist of a large number of devices and mechanical systems. Therefore, only their proper fitting in the shaft space and the optimum selection of dimensions allow for ensure the reliability and proper exploitation of the elevator shaft.

Design premises for this type of facility are subject to inspection at every stage of construction, particularly in the rough. Geodetic methods and instruments are important in the verification of elevator shaft geometry. Control measurements of elevator shafts are made to determine the deviation from the vertical plane and walls torsion of the structure $[3,4,5]$. The obtained results allow to specify the way of assembly of axes of the cabin and counterweight guide rails and to adjust the dimensions of the cabin in a way that allows for a free movement and fulfilment of the design premises $[6,7$, 8].

In the traditional approach, observations are made in a local 2D coordinate system $(X Y)$ and only elements measured in relation to this coordinate system are adjusted. This article proposes the concept of estimation of an elevator shaft control measurements results in the local 3D coordinate system ( $X Y H)$ where the conditions for adjustment at individual measurement stages are determined not only for two dimensions $(X Y)$ of the control points but also for elevations $(H)$. This approach involves conditions of placement of control points in three dimensions, which allows for a complete set of information about the geometry of the elevator shaft walls.

The elevator shaft geodetic inspection is carried out on the basis of control base, which is installed on the foundation of the shaft, below the lowest stop level on which the cabine stops. The rectangular shape is usually four points $[5,6,7,8]$. In practical applications these may also be two points. The scheme of the elevator shaft with the location of the points of the control base and control points are shown in Fig. 1. The measuring frame determines the plane $X Y$, while the vertical axis of the assumed local coordinate system is realized by direction of action of gravity.

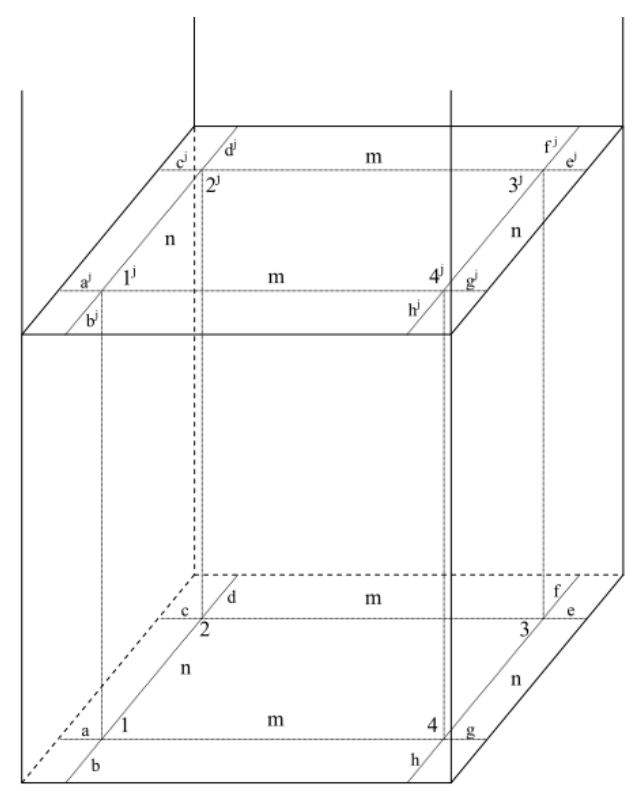

Fig. 1. Scheme of an elevator shaft.

\footnotetext{
* Corresponding author: karolina.makowska@pg.edu.pl
} 
Determination of the deviation of the shaft walls from the vertical plane is based on the designation of adjusted $X Y$ coordinates of control points for each measuring level, while defining the deviation from the horizontal plane is based on the designation of the adjusted $H$ coordinates of those points. For this purpose, the object of measurement are values on the reference level $(a, b, c, d, e, f, g)$ and values on each measuring levels $\quad\left(a^{j}, b^{j}, c^{j}, d^{j}, e^{j}, f^{j}, g^{j}\right.$, where $\quad j-$ number of measuring level).

\section{The theoretical basis}

\subsection{Parametric method with conditions on parameters}

The method described in this article applies not only to the problem of determining the deviations of walls of an elevator shaft, but can also be use to solve other problems in engineering geodesy, what is shown in the publications $[9,10]$.

The most important information about this method, which will allow for understanding of the way to solve the problem, are presented below. Detailed analysis and considerations related to the parametric method with conditions on parameters can be found in $[3,4,11,12]$.

As in publications $[3,4,9,10]$, the problem can be expressed using the system of equations:

$$
\left\{\begin{array}{l}
\mathbf{A X}+\mathbf{L}=\mathbf{V} \\
\mathbf{B X}+\mathbf{\Omega}=\mathbf{0}
\end{array}\right.
$$

where:

A , B - known coefficients' matrices,

$\hat{\mathbf{X}}$ - estimator of $\mathbf{X}$ vector,

$\mathbf{L}, \boldsymbol{\Omega}$ - free terms vectors,

$\hat{\mathbf{V}}$ - estimator of corrections' vector.

As shown in publications $[11,12]$, the solution of the above system of equations (1) is a stepwise solution. In the first stage, the vector of correlates $\hat{\mathbf{K}}$ is searched (2):

$$
\hat{\mathbf{K}}=-\left\{\mathbf{B}\left(\mathbf{A}^{\mathbf{T}} \mathbf{P A}\right)^{-1} \mathbf{B}^{\mathrm{T}}\right\}^{-1}\left\{\Omega-\mathbf{B}\left(\mathbf{A}^{\mathbf{T}} \mathbf{P A}\right)^{-\mathbf{1}} \mathbf{A}^{\mathrm{T}} \mathbf{P L}\right\}
$$

It allows to determine a vector of adjusted parameters $\hat{\mathbf{X}}(3)$ :

$$
\hat{\mathbf{X}}=-\left(\mathbf{A}^{\mathbf{T}} \mathbf{P A}\right)^{-1}\left(\mathbf{A}^{\mathbf{T}} \mathbf{P L}-\mathbf{B}^{\mathrm{T}} \hat{\mathbf{K}}\right)
$$

which is necessary to obtain an estimator of corrections' vector $\hat{\mathbf{V}}$ (4):

$$
\hat{\mathbf{V}}=\mathbf{A} \hat{\mathbf{X}}+\mathbf{L}
$$

According to previously quoted sources, the above solution may be replaced by a simplified solution. For this purpose, the equation $\mathbf{B} \hat{\mathbf{X}}+\boldsymbol{\Omega}=\mathbf{0}$ is treated as an additional equation of corrections, for which infinitely large values of weight $\mathbf{P}_{\infty}$ are assumed. From this there is a dependence (5):

$$
\mathbf{B} \hat{\mathbf{X}}+\boldsymbol{\Omega}=\mathbf{V}_{\boldsymbol{\Omega}} .
$$

This approach allows to obtain from the solution a correction value of zero. What is more, this allows to perform further calculations in a manner typical of the parametric method for which we can write a system of corrections in the form:

$$
\widetilde{\mathbf{V}}=\widetilde{\mathbf{A}} \hat{\mathbf{X}}+\widetilde{\mathbf{L}}
$$

where:

$$
\widetilde{\mathbf{A}}=\left[\begin{array}{l}
\mathbf{A} \\
\mathbf{B}
\end{array}\right] \quad \widetilde{\mathbf{L}}=\left[\begin{array}{l}
\mathbf{L} \\
\boldsymbol{\Omega}
\end{array}\right] \quad \tilde{\mathbf{V}}=\left[\begin{array}{l}
\hat{\mathbf{V}} \\
\mathbf{V}_{\mathbf{\Omega}}
\end{array}\right]
$$

The assumed weight matrix $\widetilde{\mathbf{P}}$ is:

$$
\widetilde{\mathbf{P}}=\left[\begin{array}{cc}
\mathbf{P} & \mathbf{0} \\
\mathbf{0} & \mathbf{P}_{\infty}
\end{array}\right]
$$

The simplified solution are presented below:

$$
\hat{\mathbf{X}}=-\left(\widetilde{\mathbf{A}}^{\mathbf{T}} \widetilde{\mathbf{P}} \widetilde{\mathbf{A}}\right)^{-\mathbf{1}} \widetilde{\mathbf{A}}^{\mathbf{T}} \widetilde{\mathbf{P}} \widetilde{\mathbf{L}}
$$

The use of the relation (8) allows the estimator of the correction's vector (6) to be written according to the relation:

$$
\widetilde{\mathbf{V}}=-\widetilde{\mathbf{A}}\left(\widetilde{\mathbf{A}}^{\mathbf{T}} \widetilde{\mathbf{P}} \widetilde{\mathbf{A}}\right)^{-1} \widetilde{\mathbf{A}}^{\mathbf{T}} \widetilde{\mathbf{P}} \widetilde{\mathbf{L}}+\widetilde{\mathbf{L}}
$$

\subsection{Observation equations}

For further analysis, the scheme of an elevator shaft shown in Fig. 1. was used.

In the case considered by the authors, the adjustment of acquired data is based on the use of parallelism and perpendicularity conditions that occur between the elements of an elevator shaft. The innovative character of the proposed method consists in linking the horizontal coordinates of control points to the heights of each level. Consequently, the estimation of the measurement results performed in the local 3D coordinate system using the parametric method with conditions on parameters allows simultaneous determination of corrections to the coordinates of all axes of the assumed system. This is important because other publications about the implementation of inventory measurement and adjustment of their results do not take into account the estimation of the next levels on which the measurement is made-heights are taken directly from the building project $[6,7]$.

Opposite walls of the elevator shaft should be parallel to each other, therefore, according to Fig. 1, the following parallelism conditions are assumed:

$$
\left\{\begin{array}{l}
\hat{X}_{4}-\hat{X}_{1}-k=0 \\
\hat{X}_{3}-\hat{X}_{2}-k=0
\end{array}\right\}
$$




$$
\left.\begin{array}{l}
\hat{Y}_{2}-\hat{Y}_{1}-p=0 \\
\hat{Y}_{3}-\hat{Y}_{4}-p=0
\end{array}\right\}
$$

where:

$\hat{X}_{1}, \hat{Y}_{1}, \hat{X}_{2}, \hat{Y}_{2}, \hat{X}_{3}, \hat{Y}_{3}, \hat{X}_{4}, \hat{Y}_{4}$ - adjusted coordinates of control points.

What is more, the condition of perpendicularity between individual walls should also be maintained:

$$
\left.\begin{array}{c}
\hat{X}_{2}-\hat{X}_{1}=0 \\
\hat{X}_{3}-\hat{X}_{4}=0
\end{array}\right\}
$$

Observation equations can be written according to the following relations:

$$
\begin{array}{ll}
\hat{X}_{1}^{j}=a-a^{j} & \hat{X}_{2}^{j}=c-c^{j} \\
\hat{X}_{3}^{j}=c+m+e^{j} & \hat{X}_{4}^{j}=a+m+g^{j} \\
\hat{Y}_{1}^{j}=b-b^{j} & \hat{Y}_{2}^{j}=b+n+d^{j} \\
\hat{Y}_{3}^{j}=h+n+f^{j} & \hat{Y}_{4}^{j}=h-h^{j}
\end{array}
$$

In this paper, in addition to the $X, Y$ coordinates the heights $H$ was also analyzed. Due to the contemplated assumption of a constant distance between the various measurement levels, the condition imposed on height is (10):

$$
\hat{H}_{i}-j s=0
$$

where:

$i$ - number of control point,

$j$ - number of measurement level,

$s$ - assumed distance between measurement levels.

\section{An example of practical use}

To verify the presented concept, simulated data was used.

The considerations were divided into two variants:

- variant 1: A base of four points has been adopted and $H=0$ for reference level;

- variant 2: A base of two points has been adopted and $H=0$ for reference level.

In addition, the following conditions were applied for the variants:

- for first measurement level $\hat{H}_{i}-2800=0$,

- for second measurement level $\hat{H}_{i}-5600=0$,

- for third measurement level $\hat{H}_{i}-8400=0$,

- for fourth measurement level $\hat{H}_{i}-11200=0$.

\subsection{Variant 1}

In variant 1 , four points of base, designated from 1 to 4 ,

\begin{tabular}{|c|c|c|c|c|c|c|c|c|}
\hline \multirow{3}{*}{ 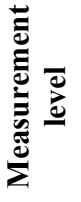 } & \multicolumn{8}{|c|}{ Number of base point } \\
\hline & \multicolumn{2}{|c|}{1} & \multicolumn{2}{|c|}{2} & \multicolumn{2}{|c|}{3} & \multicolumn{2}{|c|}{4} \\
\hline & $a$ & $b$ & $c$ & $d$ & $e$ & $f$ & $g$ & $h$ \\
\hline 0 & 350 & 300 & 350 & 300 & 350 & 300 & 350 & 300 \\
\hline 1 & 370 & 286 & 340 & 290 & 366 & 309 & 336 & 290 \\
\hline 2 & 354 & 322 & 355 & 324 & 334 & 281 & 367 & 284 \\
\hline 3 & 310 & 320 & 378 & 285 & 340 & 314 & 352 & 310 \\
\hline 4 & 314 & 324 & 367 & 294 & 342 & 310 & 358 & 320 \\
\hline
\end{tabular}
were used for analysis. Calculations were made at the reference level and four measurement levels $j$ ( $j=1,2,3,4)$. It has also been assumed that the distance between the individual measurement levels should be $2800 \mathrm{~mm}$.

The analyzes were based on the values shown in Table 1 and:

\begin{tabular}{|c|c|c|c|c|c|c|}
\hline \multirow{3}{*}{ 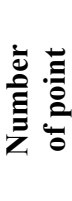 } & \multicolumn{6}{|c|}{ Coordinate } \\
\hline & \multirow{2}{*}{$\begin{array}{c}\hat{X} \\
{[\mathrm{~mm}]}\end{array}$} & \multirow{2}{*}{$\begin{array}{c}\hat{Y} \\
{[\mathrm{~mm}]}\end{array}$} & \multicolumn{4}{|c|}{$\hat{H}[\mathrm{~mm}]$} \\
\hline & & & $j=1$ & $j=2$ & $j=3$ & $j=4$ \\
\hline 1 & 0.4 & -3.1 & 2800.0 & 5600.0 & 8400.0 & 11200.0 \\
\hline 2 & 0.4 & 1996.9 & 2800.0 & 5600.0 & 8400.0 & 11200.0 \\
\hline 3 & 1900.4 & 1996.9 & 2800.0 & 5600.0 & 8400.0 & 11200.0 \\
\hline 4 & 1900.4 & -3.1 & 2800.0 & 5600.0 & 8400.0 & 11200.0 \\
\hline
\end{tabular}

$m=1200 \mathrm{~mm}, \quad n=1400 \mathrm{~mm}$,

$k=1900 \mathrm{~mm}, \quad p=2000 \mathrm{~mm}$

Table 1. Simulated data adopted to analysis - variant $1([\mathrm{~mm}])$.

Adjusted coordinates of the control points, deviations from the vertical of the shaft walls and deviations from the reference level derived from the solution described above are summarized in the Table 2, Table 3 and Table 4 (relation (9)).

Table 2. Adjusted coordinates of the control points. 
Table 3. Deviations from the vertical plane of the shaft walls ([mm]).

\begin{tabular}{|c|c|c|c|c|}
\hline \multirow{2}{*}{$\hat{\mathbf{V}}$} & \multicolumn{4}{|c|}{ Measurement level } \\
\cline { 2 - 5 } & 1 & 2 & 3 & 4 \\
\hline$d \hat{X}_{1}$ & 20.4 & 4.4 & -39.6 & -35.6 \\
\hline$d \hat{Y}_{1}$ & -17.1 & 18.9 & 16.9 & 20.9 \\
\hline$d \hat{X}_{2}$ & -9.6 & 5.4 & 28.4 & 17.4 \\
\hline$d \hat{Y}_{2}$ & 6.9 & -27.1 & 11.9 & 2.9 \\
\hline$d \hat{X}_{3}$ & -15.6 & 16.4 & 10.4 & 8.4 \\
\hline$d \hat{Y}_{3}$ & -12.1 & 15.9 & -17.1 & -13.1 \\
\hline$d \hat{X}_{4}$ & 14.4 & -16.6 & -1.6 & -7.6 \\
\hline$d \hat{Y}_{4}$ & -13.1 & -19.1 & 6.9 & 16.9 \\
\hline
\end{tabular}

Table 4. Deviations from the reference level ([mm]).

\begin{tabular}{|c|c|c|c|c|}
\hline \multirow{2}{*}{$\hat{\mathbf{V}}$} & \multicolumn{4}{|c|}{ Measurement level } \\
\cline { 2 - 5 } & 1 & 2 & 3 & 4 \\
\hline$d \hat{H}_{1}$ & -10.0 & -12.0 & -4.0 & -16.0 \\
\hline$d \hat{H}_{2}$ & -2.0 & -8.0 & -11.0 & -8.0 \\
\hline$d \hat{H}_{3}$ & -14.0 & -18.0 & -9.0 & -9.0 \\
\hline$d \hat{H}_{4}$ & -6.0 & -3.0 & -15.0 & -22.0 \\
\hline
\end{tabular}

\subsection{Variant 2}

The analysis was based on a base of two points: 1 and 3 (according to the Fig. 1). As in variant 1, four measurement levels $j=1,2,3,4$ and a distance of $2800 \mathrm{~mm}$ between them were assumed. For the analysis, the same simulated data of measured values were accepted, because of the willingness to compare the obtained results from both variants (Table 5).

Table 5. Simulated data adopted to analysis - variant 2 ([mm]).

\begin{tabular}{|c|c|c|c|c|c|c|c|c|}
\hline \multirow{3}{*}{ 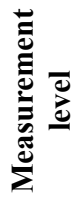 } & \multicolumn{8}{|c|}{ Number of base point } \\
\hline & \multicolumn{4}{|c|}{1} & \multicolumn{4}{|c|}{3} \\
\hline & $a$ & $m+g$ & $b$ & $n+d$ & $e$ & $m+c$ & $f$ & $n+h$ \\
\hline 0 & 350 & 1550 & 300 & 1700 & 350 & 1550 & 300 & 1700 \\
\hline 1 & 370 & 1536 & 286 & 1690 & 366 & 1540 & 309 & 1690 \\
\hline 2 & 354 & 1567 & 322 & 1724 & 334 & 1555 & 281 & 1684 \\
\hline 3 & 310 & 1552 & 320 & 1685 & 340 & 1578 & 314 & 1710 \\
\hline 4 & 314 & 1558 & 324 & 1694 & 342 & 1567 & 310 & 1720 \\
\hline
\end{tabular}

The results of the calculations are shown in Table 6 , Table 7 and Table 8.
Table 6. Adjusted coordinates of the control points.

\begin{tabular}{|c|c|c|c|c|c|c|}
\hline \multirow{3}{*}{ 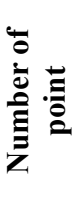 } & \multicolumn{6}{|c|}{ Coordinate } \\
\hline & \multirow{2}{*}{$\begin{array}{c}\hat{X} \\
{[\mathrm{~mm}]}\end{array}$} & \multirow{2}{*}{$\begin{array}{c}\hat{Y} \\
{[\mathrm{~mm}]}\end{array}$} & \multicolumn{4}{|c|}{$\hat{H}[\mathrm{~mm}]$} \\
\hline & & & $j=1$ & $j=2$ & $j=3$ & $j=4$ \\
\hline 1 & 4.3 & -4.8 & 2800.0 & 5600.0 & 8400.0 & 11200.0 \\
\hline 3 & 1904.2 & 1995.3 & 2800.0 & 5600.0 & 8400.0 & 11200.0 \\
\hline
\end{tabular}

Table 7. Deviations from the vertical plane of the shaft walls $([\mathrm{mm}])$.

\begin{tabular}{|c|c|c|c|c|}
\cline { 2 - 5 } \multicolumn{1}{c|}{} & \multicolumn{4}{c|}{ Measurement level } \\
\cline { 2 - 5 } \multicolumn{1}{c|}{} & 1 & 2 & 3 & 4 \\
\hline$d \hat{X}_{1}$ & 24.3 & 8.3 & -35.7 & -31.7 \\
\hline$d \hat{Y}_{1}$ & -18.8 & 17.2 & 15.2 & 19.2 \\
\hline$d \hat{X}_{3}$ & -11.8 & 20.2 & 14.2 & 12.2 \\
\hline$d Y_{3}$ & -13.7 & 14.3 & -18.7 & -14.7 \\
\hline
\end{tabular}

Table 8. Deviations from the reference level ([mm]).

\begin{tabular}{|c|c|c|c|c|}
\cline { 2 - 5 } \multicolumn{1}{c|}{} & \multicolumn{4}{c|}{ Measurement level } \\
\cline { 2 - 5 } \multicolumn{1}{c|}{} & 1 & 2 & 3 & 4 \\
\hline$d \hat{H}_{1}$ & -10.0 & -12.0 & -4.0 & -16.0 \\
\hline$d H_{3}$ & -14.0 & -18.0 & -9.0 & -9.0 \\
\hline
\end{tabular}

\section{Summary}

The method of adjustment of observations made in the local 3D coordinate system presented in the article allows to perform more detailed analyzes of the geometry of the elevator shaft. The use of appropriate geometric conditions enabled the determination of such coordinates of adjusted control points for which the deviation of the shaft walls from the vertical plane obtained at the subsequent measurement levels was as small as possible.

It should be note that for uniform observational data, the final values of the adjusted coordinates and the deviations of the wall from the vertical plane are different - differences up to $4 \mathrm{~mm}$. This value allows both methods to be considered correct, but for variant 2 the number of necessary stations of the instrument is smaller, which is an undoubted advantage of this method.

The calculations presented in the article were performed on simulated data, but it can be assumed that the proposed method can be applied successfully to determine the deviations from the vertical plane of the elevator shaft walls also for the data obtained for a real structure. 


\section{References}

1. W. F. Caspary, Concepts of network and deformation analysis (Monograph 11, School of Geomatic Engineering, The University of New South Wales, UNSW Sydney NSW 2052 Australia, 2000)

2. I. M. Abdullahi, N. A. Yelwa, International Journal of Science and Technology 6 (1), 4 (2016)

3. M. Grala, Optymalizacja wpasowania osi prowadnic dźwigowych w szybach windowych (Konferencja Zakładów i Katedr Geodezji na Wydziałach Niegeodezyjnych, 1983) (in Polish)

4. M. Grala, G. Kopiejewski, A. Wasilewski, Geodezja Inżynieryjna. Działy wybrane. (Skrypty Akademii Rolniczo-technicznej w Olsztynie, Wydawnictwo ART, Olsztyn, 1986) (in Polish)

5. $\mathrm{CH}$. Schittich, In detail designing circulation areas: stairs, ramps, lifts: routing, planning principles (Institut für internationale

Architektur- Dokumentation $\mathrm{GmbH} \&$ Col. KG, Munich, 2013)
6. M. S. Nesterionok, V. N. Veksin, Nauka i Tehnika 0 (2), 38 (2015)

7. A. Piątkiewicz, H. Urbanowicz, Dźwigi elektryczne, (WNT, Warszawa, 1966) (in Polish)

8. PN-EN 81-20:2014-10, Przepisy bezpieczeństwa dotyczące budowy i instalowania dźwigów -Dźwigi przeznaczone do transportu osób i towarów -- Część 20: Dźwigi osobowe i dźwigi towarowo-osobowe

9. D. Filipiak, W. Kamiński, Reports on Geodesy and Geoinformatics 97 / 2014, 71 (2014)

10. W. Kamiński, Reports on Geodesy

$$
\text { 94/2013, } 47 \text { (2013) }
$$

11. L. W. Baran, Teoretyczne podstawy opracowania wyników pomiarów geodezyjnych (Wydawnictwo Naukowe PWN, Warszawa, 1999) (in Polish)

12. Z. Wiśniewski, Rachunek wyrównawczy w geodezji (z przykładami) (Wydawnictwo UWM, Olsztyn, 2005) (in Polish) 